\title{
The Challenges Faced by Visual Impairments in Buying Clothes and How to Wear Clothes
}

\author{
Khairi Asyraf Abdul Karim \\ Fashion Department, Faculty of Art \& Design, Universiti Teknologi MARA Perak Branch, \\ Seri Iskandar Campus, 32610 Seri Iskandar, Perak, MALAYSIA \\ Author email: khairikarim@uitm.edu.my
}

Published: 28 September 2020

\begin{abstract}
The basis of this project is to make clothing tags using an appropriate font with a braille touch that is specially designed with complete clothing details and a guide to wearing clothes. The purpose of this study is to overcome the challenges of buying and wearing clothing. This study was conducted with an interview method that focuses on the target age range 25 to 35 years in the area of Brickfields, Kuala Lumpur.
\end{abstract}

Keywords: Visually Impaired; Vision Impaired; Visual Disorder; Low Vision; Blind; Braille Touch; Clothing Tags

eISSN: 2550-214X (c) 2020. The Authors. Published for Idealogy Journal by UiTM Press. This is an Open Access article distributed under the terms of the Creative Commons Attribution-NonCommercial-NoDerivatives License (http://creativecommons.org/licenses/by-nc-nd/4.0/), which permits non-commercial re-use, distribution, and reproduction in any medium, provided the original work is properly cited, and is not altered, transformed, or built upon in any way.

\section{INTRODUCTION}

Eyes are a major physical asset used in everyday life. This vision problem is a serious problem and limiting the visually impaired people to perform various jobs at the same time and sometimes this group needs help in doing things.

This group has the right to live as normal human beings in life. Therefore, the needs and facilities that they need in going through the passage of today's sophisticated era. Not only in terms of physical help but also in the form of product creation or manual for their future use.

Clothing is the basic necessity for everyone not to be excluded from the visually impaired people. So, the facility in buying clothes and how to wear clothes needs to be emphasized because it is the daily use. It may not cause problems for ordinary people to buy clothes and wear them, but it is difficult for these visually impaired to buy their own clothes without help and wear them without knowing the details of the front and back or outside and inside.

The existing facilities do not meet the needs of the visually impaired people and not all user friendly, especially for the people of the veteran group. When these needs and facilities can be fulfilled, the visually impaired people can purchase their own clothes without assistance and find out the details of clothing such as size, colour, and how to care for it.

It will help those who do not like to rely on others but more independent in doing various activities. Various things need to be emphasized to enable these visually impaired people to enjoy life like normal people. This paper will determine the need for visually impaired people related to clothing. 


\subsection{Background}

Visually impaired or blind is a condition of impaired vision or loss of vision. Visual disorders can occur between various ages and different levels of interference. Various scales are erected to reflect the level of vision impaired and define the blindness.

The completely blind is entirely a thorough defect of all the senses of light and medically recorded (clinical) as NLP, which is a short form of 'no light perception'. For partially blind, the vision is blurred and very unclear. This means those who are certified partially blind have to stand 20 feet away from an object to see what normal people can see at a distance of 200 feet.

Blindness or visual impairment is defined as visual acuity less than $3 / 60$, or equivalent loss of visual field of fewer than 10 degrees. The definition given by the World Health Organization (WHO) according to the International Statistical Classification of Diseases, Injuries, and Causes of Death is blindness and limited vision.

For blindness, an individual is said to be blind when having visibility in the best eye after correction is less than 3/60. For limited vision, an individual is said to have a limited vision when the visibility of the vision in the best eye after correction is less than $6 / 18$ to $3 / 60$ or the field of vision is less than 10 degrees from the fixation point.

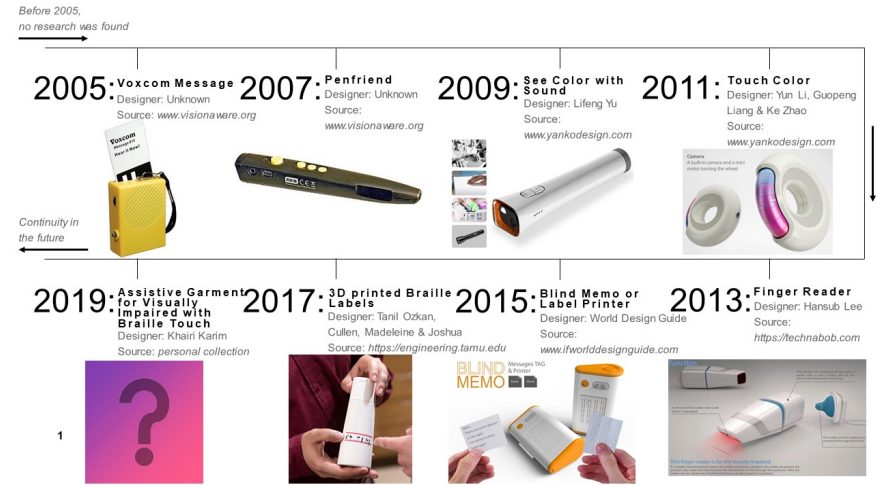

Figure 1: Industrial Revolution: Timeline from 2005 to 2017 (Khairi Karim, 2020).

Nowadays, various challenges and obstacles are faced by visually impaired people in terms of clothing. For example, there are not many facilities that can help them get clear and complete details about clothing while shopping. In this study, the braille touch and the appropriate font writing on the clothing tag play an important role to overcome this problem. Various technologies are available to help the visually impaired namely Voxcom Message, Touch Colour, Finger Reader, Blind Memo, etc.

\subsection{Description of Issues}

In the daily activity of people with disabilities, the self-management of each individual is definitely different as it depends on the physical deficiencies he or she is experiencing. But when it involves the lack of visibility, many things limit their movement that involves daily obligatory activities.

Referring to surveys through the internet, these visually impaired people will ask for help from shop workers or their own family members or friends in choosing clothes when shopping or wearing them.

But they are also exposed to today's technology that can provide information only through the fingertips by scanning the goods to obtain information. Even in the passage of this increasingly modern age, not all visually impaired people can follow it and have a shortage of using this automated method. 
Eventually, they will back to a manual method that applies since first. For example, purchased clothing will be encoded using buttons, pins, or patterned stickers to distinguish front and back, outside and inside, color, and pair of clothing.

Here can be seen that the differences in the way of self-management for each individual of the visually impaired people depend on age, the technology sector, and the constraints faced that force them to follow the automatic method or back to a more conventional manual method.

In this study, by creating a special design of clothing tags that are effective and easy in receiving information on clothing details can help the visually impaired people to manage their daily activities better.

\subsection{Product Review}

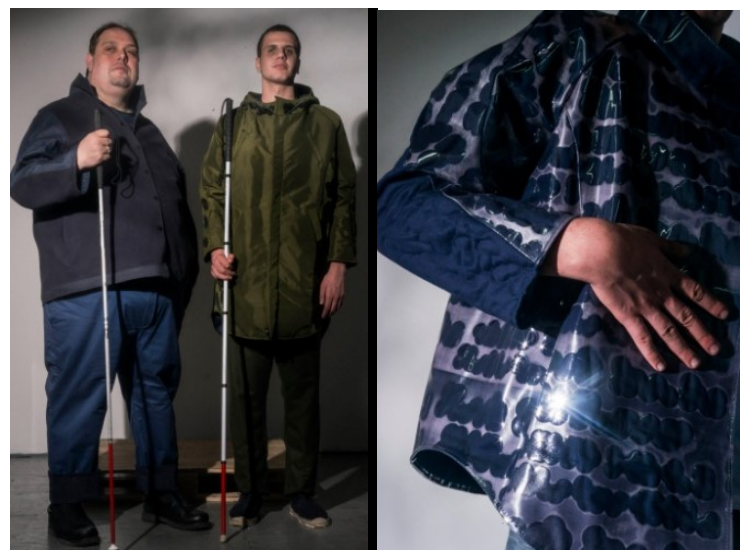

Figure 2: Self-navigating designs by Chiriboga in June 2017.

Camila Chiriboga, a graduate of Parsons School of Design, and began researching and designing special clothing for the blind. She participated in the "Disrupt Aging Design Challenge" and the American Association of Retired Persons (AARP) in exploring design that is rewarding, rethinking that combines the needs of fashion users to inspire design based on the concept of troubleshooting. She designs a wide variety of jackets and sweaters, all reversible, and can be matched with any outfit. She also created a tagging system, where each garment label contained a colour code (in braille) and a QR code that could be scanned to produce an audio description of the outfit. Finally, she won the competition by receiving an appreciation prize of $\$ 5000$.

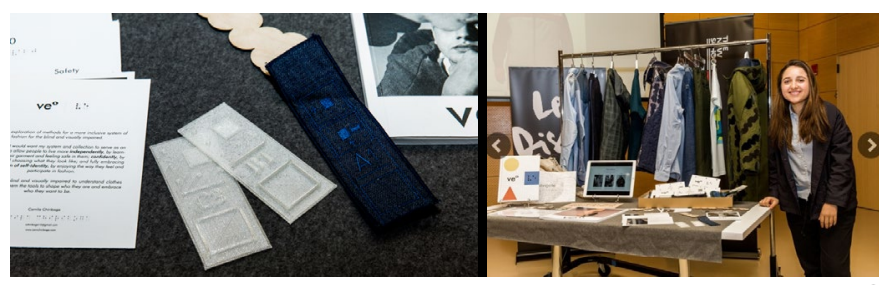

Figure 3: Each tag contains a colour code and a scanned QR code.

\section{METHODS}

In this study, there were four organizations in Brickfields, Kuala Lumpur to obtain factual information namely the Malaysia Association for The Blind (MAB), National Council for The Blind Malaysia (NCBM), Society of The Blind in Malaysia (SBM), and Malaysian Foundation for The Blind (MFB). In Malaysia, these visually impaired people are very difficult to find and their group is very limited. So, with these special organizations, all the latest and valid information can be obtained. 
This study uses a descriptive method that is conducting interviews with respondents. First, identify and examine the problem through the internet and look around to prepare the questions that will be asked about it that is happening in Malaysia.

Through this descriptive method, relies on data collection to interpret the results of the interview. The selection of this method is because the data collection process is easier to understand by interpreting facts. It is also easier to analyzed and explain.

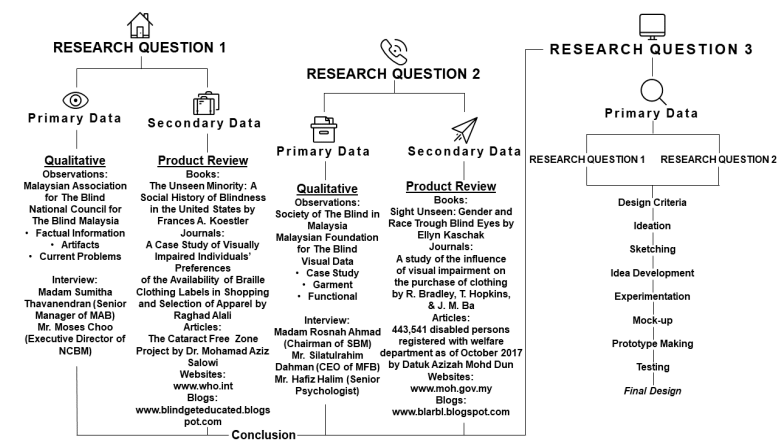

Figure 4: Research design of the study (Khairi Karim, 2020).

This study uses primary and secondary data methods to gather the necessary information. For primary data, observations were carried out to study the challenges faced by visually impaired people to buy their clothes and how they wearing clothes.

The qualitative method will be created by interviewing visually impaired group aged 25 to 35 years. This study is concentrated in urban areas as their population is more than in rural areas. For secondary data, the collection of information is by using books, journals, articles, newspapers, websites such as blogs and social media.

\section{ANALYSIS AND FINDINGS}

Based on this study, visually impaired people have difficulty managing their daily activities without assistance. Indirectly, it relates to clothing that is already worn on a daily basis and at all times. In general, it can be seen that these visually impaired people will go through challenges when shopping for clothes as well as how to wear them and manage clothes such as washing and ironing.

With special facilities, it can help them identify the entire details of clothing. But every convenience that exists now, all come from foreign countries such as in the West, Japan, and China. Therefore, it has to be purchased online and this will incur high costs to pay for the product or application in addition to the delivery cost.

Not only that, but the organization or association of the visually impaired groups in Malaysia also does not have a fund that can accommodate the purchase to provide the gadget for each of their members personally. No more special gadgets or applications designed for them from Malaysia. Therefore, they still use the manual method to choose, wear, and buy clothes until now. 


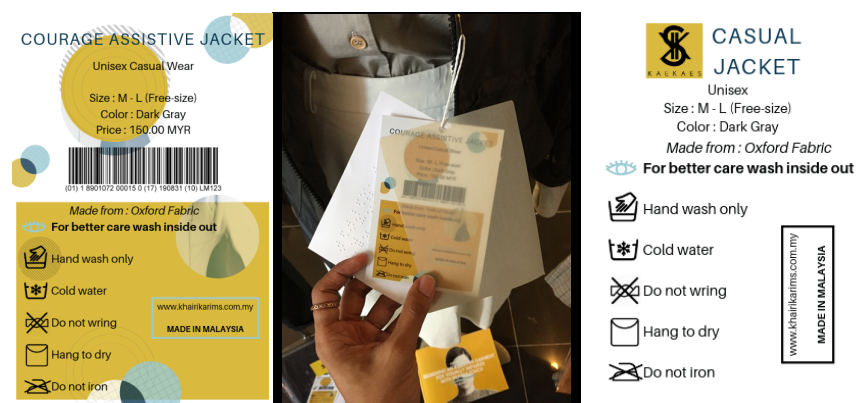

Figure 5: Braille tag with the information of size, price and care label (Khairi Karim, 2020).

The purpose of this study is to assist the visually impaired group to undergo daily activities related to clothing to facilitate the process of wearing clothes, how to identify clothes and activities to buy clothes. Perhaps this study still maintains the manual method but it is still relevant to use. In addition, it remains closely related to the latest technology in its manufacturing process.

In addition, it actually makes it easier for visually impaired people to use this method without having to take time to learn because they have used the manual method before. Undoubtedly the gadget or application technology is now introducing an automated method easier, but it is actually timeconsuming to install it when they want to use, need to choose the right option before scanning and there are some gadgets or applications that need internet control at the same time for the process it.

Other than that, it also uses a battery and needs to be charged before using it. So, in the convenience and sophistication of technology today, it is also difficult for the visually impaired to use it. By using the manual method, it is a very practical approach in helping them dress up and at the same time teaching them to live independently in the future.

\section{CONCLUSION}

Vision is the main use in the human body. Loss of vision will have a huge impact on the individual. Most of the visual impairments are caused by illness and malnutrition. According to WHO estimates, most causes of blindness worldwide are cataracts $(47.8 \%)$, glaucoma $(12.3 \%)$, uveitis $(10.2 \%)$, agerelated macular degeneration (AMD), trachoma (3.6\%), optical corneal obstruction $(5.1 \%)$ and diabetic retinopathy $(4.8 \%)$, among other causes.

In Malaysia, blindness to all levels accounted for $0.2 \%$ and low visibility covers $2.44 \%$ (based on National Eye Survey 1996). Most of the visually impaired people can still see a little in a fuzzy or vague situation. While some of them use sticks (blind wand) as a guide, it does not mean they are totally not able to see anything.

The dressing is a major necessity on a daily basis for each individual. The care of clothes also plays an important role to clean it. It may be easy to manage by normal people, but the difficulty faced by visually impaired people in terms of buying clothes and wearing clothes.

In this study, clothing tags specially designed to help the visually impaired people receive complete details in terms of clothing type, material, price, size, colour, and care. The tag contains braille touch and information with the appropriate font size for those who can still read even in vague or blurry conditions. At the same time, the tag can be scanned using a suitable application for them to get information from clothing tag details.

This study is to document for future use. Through this study, it can be used in overcoming other problems that are also faced and become a challenge for the visually impaired people. Not only clothes but also other items that are the main use for our daily life such as food, drinks, and household products. In order for this study to be a continuation and reference for researchers. 


\section{ACKNOWLEDGMENT}

First and foremost, I would like to express my gratitude to Allah S.W.T. for all the blessings. I would like to thank Faculty of Art \& Design at Universiti Teknologi MARA for the dedicated involvement in every step throughout the process. Most importantly, none of this could have happened without my family.

\section{REFERENCES}

Alicia Aledo. (2002). Tag for Attaching to a Garment Having an Attribute and Identifying the Attribute to a Person Unable to Visually Identify The Attribute. United States Patent, 1-5.

Blindness and vision impairment. (2018). Retrieved from https://www.who.int/news-room/factsheets/detail/blindness-and-visual-impairment

Dr. Mohamad Aziz Salowi. (2016). Express: Newsletter of the Malaysian Society of Ophthalmology (MSO).

Hinali Shah. (2017, June 5). Student Designs Self-Navigating Fashion Line for the Blind. Retrieved from https://www.metropolismag.com/design/student-design-self-navigating-fashion-lineblind/pic/26207/

Michela Tavolieri. (2018, June 28). Clothing Choices for the Blind and Visually Impaired. Retrieved from http://www.perkinselearning.org/technology/blog/clothing-choices-blind-and-visuallyimpaired

R., Bradley, T., Hopkins, \& J., M., Ba. (2000). A study of the influence of visual impairment on the purchase of clothing. The British Journal of Visual Impairment, 79-81.

Raghad Alali. (2017). A Case Study of Visually Impaired Individuals' Preferences of the Availability of Braille Clothing Labels in Shopping and Selection of Apparel. Applied Sciences and Technology, 6-17.

Rohit C., Khanna. (2018). Estimates of visual impairment and its causes from the National Eye Survey in Malaysia (NESII). Research Article, 1-11.

SA., Rogers. (2010, April 5). 12 Ingenious Gadgets \& Technologies Designed for the Blind. Retrieved from https://weburbanist.com/2010/04/05/12-ingenious-gadgets-technologies-for-the-blinVladimir Kulyukin, \& Aliasgar Kutiyanawala. (2010). Accessible Shopping Systems for Blind and Visually Impaired Individuals: Design Requirements and the State of the Art. Article in The Open Rehabilitation Journal, 158-168. 